\title{
Effects of Red and Blue Light during the Incubation of Turkey Eggs on Hatchability Performance and Expression Pattern of Some Myogenic Regulatory Genes
}

\author{
Walaa Slouma Hamouda Abd El Naby ${ }^{1}$, Heba Abdo Basha ${ }^{2}$, Samya Erian Ibrahim ${ }^{3}$, and Magda Ismail Abo-Samaha ${ }^{2}$ \\ ${ }^{1}$ Genetics and Genetic Engineering in Department of Animal Husbandry and Animal Wealth Development, Faculty of Veterinary Medicine, Alexandria \\ University, Egypt \\ ${ }^{2}$ Poultry Breeding and Production in the Department of Animal Husbandry and Animal Wealth Development, Faculty of Veterinary Medicine, \\ Alexandria University, Egypt \\ ${ }^{3}$ Rabbit, Turkey, and Waterfowl Breeding Research Department, Animal Production Research Institute, Egypt \\ *Corresponding author’s Email: heba.basha@alexu.edu.eg; ORCID: 0000-0003-1680-9616
}

Received: 20 Jan. 2021

Accepted: 07 Mar. 2021

\begin{abstract}
The present study aimed to investigate the effects of different light colors on hatching potential traits, including egg weight loss, scientific and commercial hatchability, mortality percentages, hatching wight as well as mRNA expression levels of some muscle growth marker genes (Myogenin, MyoD1, and FGF2) of pectoralis muscle in hatched and non-hatched non pipped Black Bronze turkey chicks. A total of 1500 hatching Black Bronze turkey eggs were assigned equally to three incubation treatment groups, namely dark (control group), red, and blue LED light (treated groups) for 25 days of the incubation period. Results indicated that colored lighting stimuli (red and blue) significantly affected hatching capability. This issue could also affect the expression of muscle growth marker genes in hatched and non-hatched non pipped turkey chicks. Incubation of turkey eggs under red or blue LED light showed an insignificant effect on mortality percentages. It can be concluded that the use of a red or blue light system during turkey eggs' incubation could improve hatchability via upregulating the expression of muscle growth marker genes.
\end{abstract}

Keywords: Hatchability, Incubation, Light color, Marker Gene expression, Turkey

\section{INTRODUCTION}

The success of artificial incubation of avian eggs relies mainly on the environmental conditions inside the incubator. Temperature (Noiva et al., 2014), humidity (Bruzual et al., 2000), ventilation (Okur et al., 2018), and egg turning (Elibol and Brake, 2006) are the four main factors controlling the hatchability percentage. Many studies suggested that monitoring the light during the incubation period has a crucial role in the achievement of successful incubation of avian eggs (Fairchild and Christensen, 2000; Archer, 2015; Huth and Archer, 2015). Introducing light during incubation improved hatchability (Shafey, 2004; Archer and Mench, 2014) and embryonic growth rate (Cooper et al., 2011), as well as reducing early and late embryonic mortality (Shafey and Al-Mohsen, 2002), and post-hatch stress (Archer and Mench, 2014). Furthermore, the light during incubation stimulated opsin expression in photoreceptors (Rozenboim et al., 2013), increased growth and differentiation of myoblast, and myofiber synchronization (Halevy et al., 2006). Moreover, avian scientists have revealed that the impact of light on the embryonic development of different birds' species depends on the color (Tong et al., 2015). Generally, the light plays a crucial role in various scientific aspects. Light is electromagnetic radiation, classified into invisible and visible radiation. Invisible radiation has wavelengths too large or too small for the biological limitations of our discernment. However, the visible light is separated into different wavelengths ranged from violet color (the shortest wavelength) to red color (the longest wavelength). Yang et al. (2016) categorized the light spectrum according to the wavelength into long (red at $610-760 \mathrm{~nm}$, yellow at 580-590 nm light) and short (green at 510-530 $\mathrm{nm}$, and blue at 450-500 $\mathrm{nm}$ light).

During embryogenesis, the development of the skeletal muscle depends on myogenic regulatory factors (MRFs) which are a family of basic helix-loop-helix transcription factors important for the proliferation and differentiation of satellite cells (Schultz and McCormick, 
1994). Satellite cells are the primary donors to muscle growth and regeneration (Relaix, 2006; Biressi and Rando, 2010). MRFs include myogenic factor 5 (Myf5), myogenic differentiation 1 (MyoDl), Myogenin, and MRF4 (Buckingham and Rigby, 2014; Zammit, 2017). When muscle stem cells (satellite cells) are activated, these $M R F$ genes are expressed in a consecutive pattern. During the proliferation of muscle stem cells, the MyoD and Myf5 genes are expressed, and after that, Myogenin is expressed as the cells begin to differentiate (Cornelison and Wold, 1997). Fibroblast growth factor 2 (FGF2) is a potent regulator of muscle cell proliferation and differentiation (Velleman, 1999). It also plays a serious role in the maintenance of satellite cells' self-renewal by inhibiting their differentiation (Pawlikowski et al., 2017). Furthermore, FGF2 has shown a possible influence on tissue regeneration and repair (Yun et al., 2010). Until now, few studies have investigated the relationship between hatching potentiality and molecular alterations of muscle growth related genes of turkey embryos incubated under different wavelengths of light. The present study aimed to investigate the effects of red and blue light stimuli during the incubation of Black Bronze turkey eggs on hatchability performance and expression profile of some muscle growth marker genes as a trail to understand the strategy of light color effect on hatching improvement.

\section{MATERIALS AND METHODS}

\section{Ethical Approval}

All experimental procedures and management conditions used in this study were approved by the local ethics committee of animal use, Faculty of Veterinary Medicine, Alexandria University, Egypt.

\section{Fertile eggs and incubation condition}

A total of 1500 hatching Black Bronze turkey eggs were collected from the Research Centre, Mahalet Mousa Station, Kafr El Sheikh Province, and were randomly allotted to three groups. The first group (control) was incubated at a complete dark incubator avoiding penetration of external light by covering incubator windows and door with black sheets, the second and the third ones were incubated under red LED light and blue LED light for the first 25 days of the incubation period. Light intensity was $12 \mathrm{~W} / \mathrm{m}^{2}$ at the top surface of the eggs with a wavelength of $610-760 \mathrm{~nm}$ for the red light and 450-500 nm for the blue light. Incubator and hatcher were fumigated using formaldehyde gas by mixing of $40 \mathrm{ml}$ formalin $40 \%$ and $20 \mathrm{gm}$ potassium permanganate
(KMNO4) per three cubic meters. Diluted TH4 solution $(2 \mathrm{ml} / \mathrm{L})$ was sprayed on the eggs as a disinfectant before the incubation. All groups were incubated at normal incubation conditions $\left(37.5^{\circ} \mathrm{C}, 65 \%\right.$ relative humidity, and turning automatically every three hours by angle \pm 45). After 25 days of incubation, the eggs were transferred to the hatcher $\left(37^{\circ} \mathrm{C}, 75 \%\right.$ relative humidity, and no turning). During incubation, 100 eggs from each group were individually weighted every week to estimate the weight loss. Candling of the incubated eggs was performed on the seventh day of incubation to check whether the eggs are fertile or not and inspect early mortality percentage. At 14 and 25 days of incubation, eggs were candled again to determine mid, and late embryonic mortality percentages. The hatchability percentage was determined as the number of viable chicks hatched divided by the total eggs set (commercial hatchability) or fertile eggs set (scientific hatchability). The non-hatched eggs were left for an extra one day later hatching in the hatcher to give further chance to hatch. The number of hatched and non-hatched non-pipped eggs were recorded. Newly hatched chicks on the first day were weighted.

\section{Sample collection}

The pectoralis muscle samples were collected from hatched and non-hatched non-piped chicks (four samples from each group) then homogenized, immediately snapfrozen in liquid nitrogen, and stored in $-80^{\circ} \mathrm{C}$.

\section{Total RNA isolation and cDNA synthesis}

Total RNA was isolated from homogenized muscle tissue using the Biozol reagent (Bioflux, Japan) according to the manufacturer's recommendations. The SensiFAST ${ }^{\text {тм }}$ cDNA Synthesis Kit (Bioline, United Kingdom) was used for cDNA synthesis according to the manufacturer's instructions. Briefly, $4 \mu \mathrm{l}$ of total RNA was mixed with $4 \mu 15 \mathrm{X}$ buffer, $1 \mu \mathrm{l}$ reverse transcriptase and $11 \mu 1$ RNase free $\mathrm{H}_{2} \mathrm{O}$. The reaction was carried out as follows: $25^{\circ} \mathrm{C}$ for $10 \mathrm{~min}, 42^{\circ} \mathrm{C}$ for $15 \mathrm{~min}$ (reverse transcription), and $4^{\circ} \mathrm{C}$ holds. The cDNA was tested by amplification of the $\beta$-actin gene, and then stored at $-20^{\circ} \mathrm{C}$.

\section{Quantitative real-time PCR}

The quantitative real-time PCR was carried out to investigate the expression levels of Myogenin, MyoDl, and FGF2 genes as described previously (Abd El Naby and Basha, 2018). The primer sequences designed by using (https://primer3.ut.ee/) are listed in Table 1. The $\beta$ - 
actin (housekeeping gene) was used as normalizer. The relative mRNA expression was calculated using the comparative Ct method $\left(2^{\left(-\Delta \Delta^{\mathrm{ct}}\right)}\right)$, and the results were reported as the fold change \pm SD (Rao et al., 2013).

\section{Statistical analysis}

The Chi-square test was used to determine the relationship between the light color (dark, red, and blue) during the incubation period and the number of hatched or non-hatched non pipped chicks of Black Bronze turkey ( $p$ $\leq 0.05$ ). Other data were analyzed by one-way ANOVA using SAS (Statistical Analysis System, version 6, $4^{\text {th }}$ Edition, SAS Institute, USA). Data are expressed as mean $\pm \mathrm{SE}$ and $\mathrm{p} \leq 0.05$ were considered significant. Analyses of significant main effects were performed using multiple range comparisons with Duncan multiple range test. However, gene expression data were statistically analyzed by GraphPad Prism software version 6 (GraphPad Prism Software, La Jolla, California, USA) using one-way ANOVA.

Table 1. Primers used for quantitative real-time PCR

\begin{tabular}{llc}
\hline Genes & \multicolumn{1}{c}{ Primer Sequence (5-3) } & $\begin{array}{c}\text { Amplicon size } \\
\text { (base pair) }\end{array}$ \\
\hline Myogenin (NM_001303170.1) & F: CTCTCTGAGCTGGAAACGGG & 86 \\
MyoD1 (NM_001303171.1) & R: GGTCCACAGTGTTGGAGGAT & 63 \\
& F: CATGGGAAGAGTTCCGTTGT & 84 \\
FGF2 (XM_003205699.3) & R: GGAAATCCTCTCCACAATGC & 120 \\
3-actin (NM_001303173.1) & F: CTGGCACTGAAATGTGCAAC & \\
\hline
\end{tabular}

MyoD1: Myogenic factor D1, FGF2: Fibroblast growth factor, and $\beta$-actin: Beta actin; F: forward, R: reverse.

\section{RESULTS}

The relationship between light color and the number of hatched or non-hatched non-pipped chicks

The statistical analysis showed that 13.85 is the estimated Chi-Square value ( $\mathrm{p} \leq 0.05)$, indicating that the hatching ability of fertile Black Bronze turkey eggs depends on light color during the incubation period.

Effect of different lighting color during the incubation period on the hatching performance

The results showed that weekly weight loss of Black Bronze turkey eggs incubated at dark, red, and blue light had no significant difference at all incubation periods (Table 2). However, the incubated eggs in darkness had the highest significant total weight loss, compared to incubated eggs exposed to red and blue light.

Table 3 showed that the application of colored light significantly increased the scientific and commercial hatchability percentages of turkey eggs. Incubation under red light exhibited the highest scientific and commercial hatchability percentages, while the lowest hatchability was recorded for the dark condition. Additionally, early, mid, and late mortality percentages did not show significant differences between colored incubation or dark management. Furthermore, the hatching weight of turkey chicks showed that eggs exposed to the red light in the incubator had the highest significant hatching weight $(50.87 \mathrm{gm})$ than the other groups.

Effect of different lighting color during the incubation period on the expression profile of Myogenin, MyoD1, and FGF2 genes of turkey chicks

The effects of different light colors during the incubation period on mRNA expression levels of muscle growth marker genes in hatched and non-hatched nonpipped chicks are shown in figures 1 and 2. Red and blue light colors induced changes in the expression patterns of Myogenin, MyoD1, and FGF2 genes, compared to control (figures 1 and 2). Hatched chicks exposed to the red light during incubation showed increased Myogenin and MyoDI expression levels with $14.65 \pm 2.27$ and $19.01 \pm 2.70$ folds than in case of blue light exposure $(8.5 \pm 1.6$ and $3.64 \pm 1.35$ fold) relative to control (figures $1 \mathrm{a}$ and $\mathrm{b}$ ). The Myogenin level was significant $(\mathrm{p} \leq 0.05)$ upregulated (59.98 \pm 0.04 fold) in non-hatched non-pipped chicks were exposed to blue light during the incubation period relative to control (Figure 2a). Its relative expression level also increased in non-hatched non-pipped chicks exposed to red light, but it was less than blue color. Moreover, the MyoDl mRNA expression profile showed significant ( $\mathrm{p} \leq$ $0.05)$ upregulation $(38.85 \pm 0.96$ folds) in non-hatched 
chicks exposed to red light during the incubation period relative to control (Figure 2b) and increased (5.86 \pm 1.33 folds) in case of blue light. Meanwhile, the FGF2 gene revealed different expression patterns in both hatched and non-hatched non-pipped chicks. However, their relative expression levels showed a significant $(\mathrm{p} \leq 0.05)$ increase with $7.00 \pm 0.45$-fold in hatched chicks exposed to blue light (Figure 1c), and $5.24 \pm 1.1$ fold in the non-hatch nonpipped chicks exposed to red light during incubation relative to control (Figure 2c).

Table 2. Effect of the different lighting colors during incubation on egg weight loss of Black Bronze turkey eggs

\begin{tabular}{|c|c|c|c|}
\hline \multirow{2}{*}{$\begin{array}{l}\text { Incubation period } \\
\text { (Day) }\end{array}$} & \multicolumn{3}{|c|}{ Egg weight loss in different light conditions (g) } \\
\hline & Dark & Red & Blue \\
\hline $1-7$ & $1.117 \pm 0.256$ & $1.422 \pm 0.079$ & $1.300 \pm 0.199$ \\
\hline $7-14$ & $4.298 \pm 0.334$ & $2.653 \pm 0.226$ & $1.714 \pm 0.256$ \\
\hline $14-21$ & $4.941 \pm 0.333$ & $2.869 \pm 0.295$ & $2.984 \pm 0.388$ \\
\hline $21-25$ & $5.399 \pm 0.297$ & $4.395 \pm 0.411$ & $4.983 \pm 0.444$ \\
\hline Total & $15.872 \pm 0.541^{\mathrm{a}}$ & $11.554 \pm 0.585^{\mathrm{b}}$ & $10.179 \pm 0.442^{b}$ \\
\hline
\end{tabular}

Means within the same row with different superscripts are significantly different $(\mathrm{p} \leq 0.05)$.

Table 3. Effect of the different lighting colors on hatchability, mortality percentages and hatching weight of Black Bronze turkey eggs

\begin{tabular}{llccc}
\hline Variable & \multicolumn{1}{c}{ Light group } & Dark & Red & Blue \\
\hline Hatchability (\%) & Scientific & $80.58 \pm 0.932^{\mathrm{c}}$ & $90.43 \pm 0.785^{\mathrm{a}}$ & $87.73 \pm 0.543^{\mathrm{b}}$ \\
& Commercial & $69.24 \pm 0.88^{\mathrm{b}}$ & $76.67 \pm 0.97^{\mathrm{a}}$ & $73.45 \pm 1.23^{\mathrm{a}}$ \\
\hline \multirow{2}{*}{ Mortality (\%) } & Early & $1.50 \pm 0.005$ & $2.43 \pm 0.010$ & $1.00 \pm 0.033$ \\
& Mid & $3.00 \pm 0.002$ & $4.55 \pm 0.001$ & $2.30 \pm 0.003$ \\
\hline Hatching weight (gm) & Late & $18.36 \pm 0.024$ & $20.12 \pm 0.096$ & $22.88 \pm 0.176$ \\
\hline
\end{tabular}

Means within the same row with different superscripts are significantly different $(\mathrm{p} \leq 0.05)$.

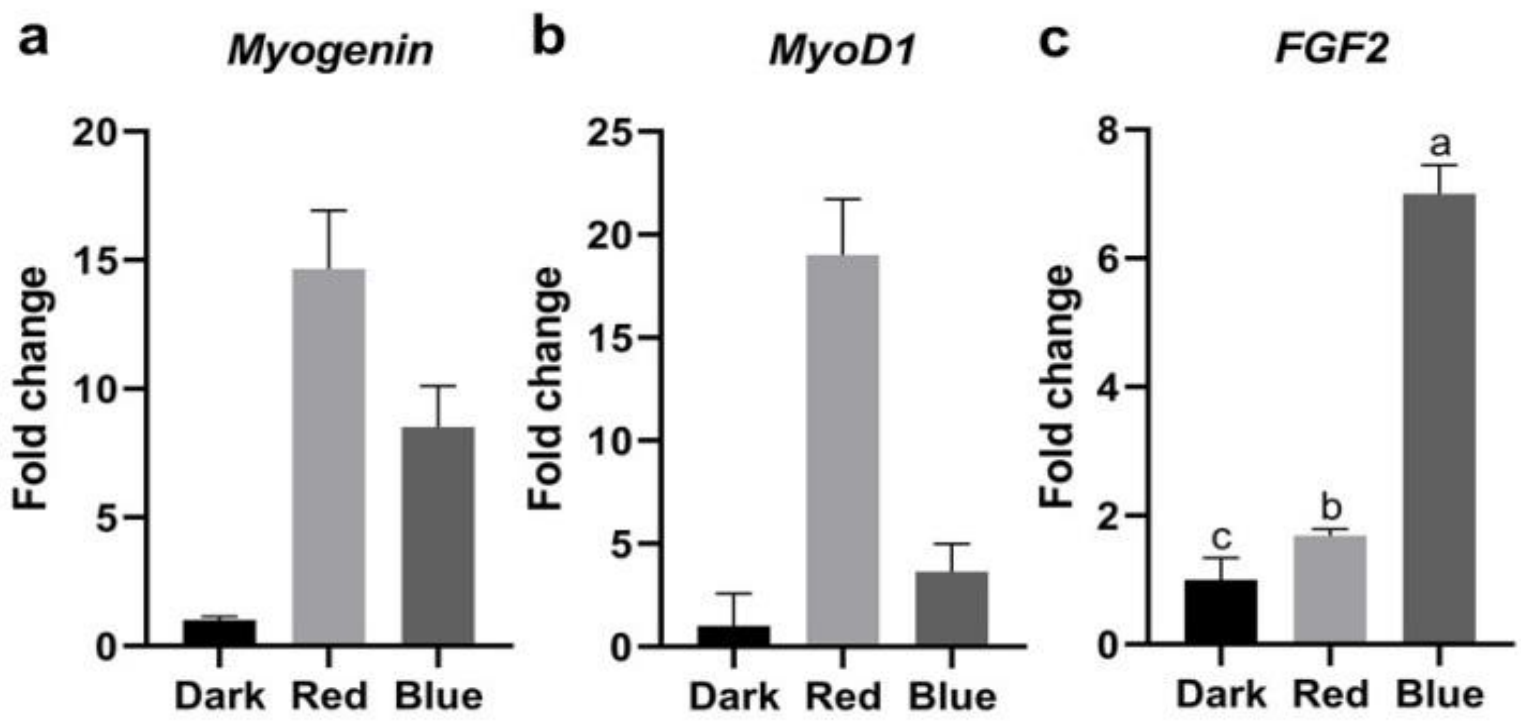

Figure 1. The relative expression levels of Myogenin, MyoD1, and FGF2 genes in hatched turkey chicks with different light color treatments during egg incubation. Different letters in columns mean significant differences $(\mathrm{p} \leq 0.05)$. 

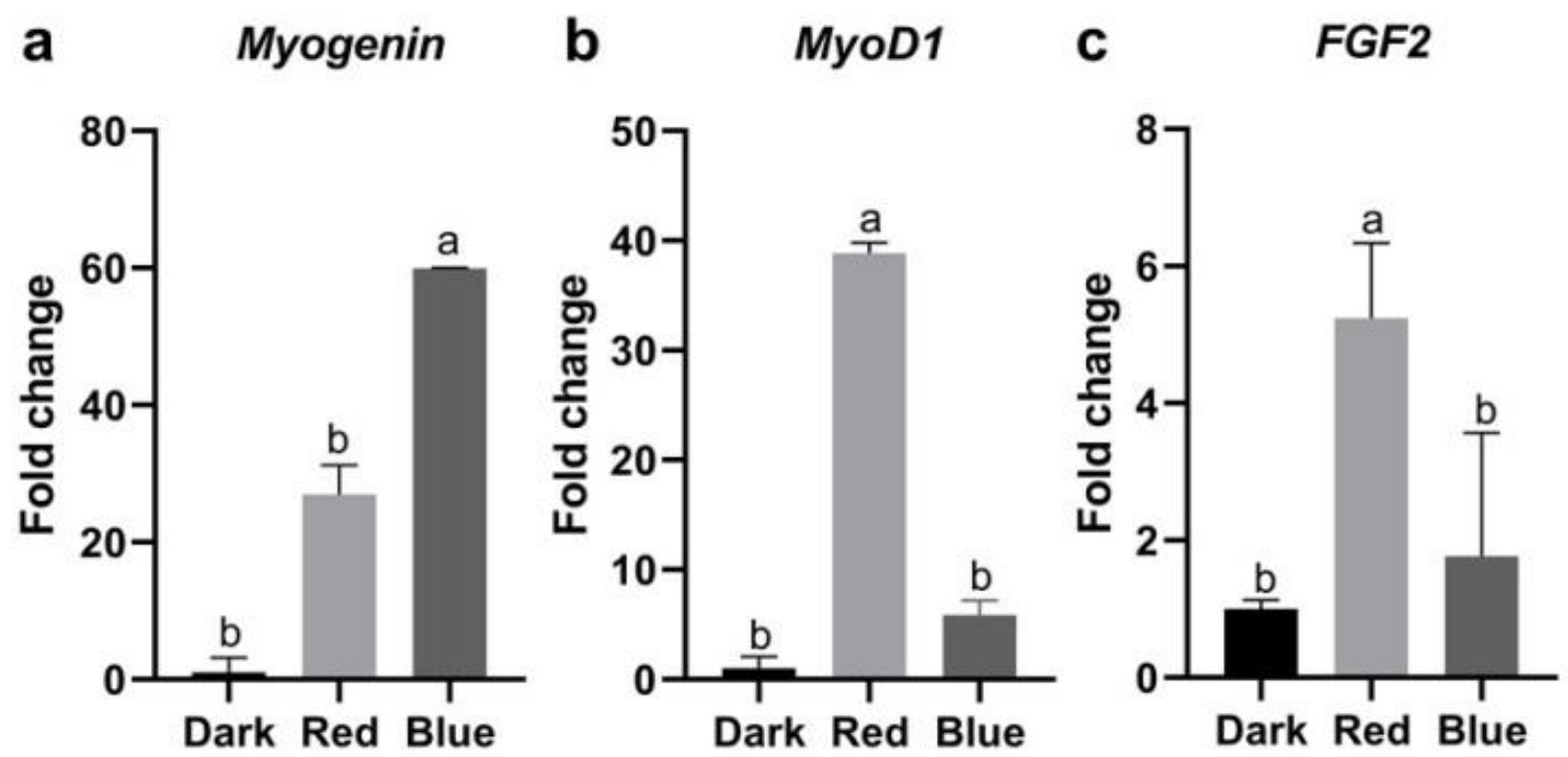

Figure 2. The relative expression levels of Myogenin, MyoD1, and FGF2 genes in non-hatched non-pipped turkey chicks with different light color treatments during egg incubation. Different letters in columns mean significant differences $(\mathrm{p} \leq 0.05)$.

\section{DISCUSSION}

Avian embryogenesis is strongly influenced by the light wavelength and color (Shafey and Al-Mohsen, 2002; Rozenboim et al., 2013). The present study investigated the impact of colored light of different wavelengths on the hatchability performance of Black Bronze turkey. The results showed that using red or blue light in the first 25 days of incubation of Black Bronze turkey eggs improved scientific and commercial hatchability percentages. Incubation of Black Bronze turkey eggs in red light resulted in the highest improvement of hatchability percentages as well as hatching weight. However, weekly egg weight loss, mortality percentages (Early, mid, and late) were not significantly affected by colored light during incubation. These results are compatible with a study conducted by Archer (2015) indicating that red light is the success key of hatchability for broiler or layer eggs. Moreover, Archer (2017) ensured that the incubation of broiler eggs under red or white light could improve hatchery efficiency in comparison with the green light. ElKomy et al. (2017) reported increased hatchability and decreased mortality percentages for quail and Cobb 500 broiler breeder's eggs exposed to red light. Contrary to findings of the current study, providing $30 \mathrm{~lx}$ green LED light during the incubation of Arbor Acres fertile broiler eggs had no detrimental effect on the development of eyes, heart, and liver of embryos (Zhang et al., 2016). Santos (2019) also found no impact of red or blue light on the hatching behavior of Lohmann White and Brown eggs during incubation.

In this study, both light color stimuli (red and blue) upregulated Myogenin, MyoD1, and FGF2 in the embryonic stage and improved hatching capability compared to the group incubated in the dark condition. The Myogenin gene was upregulated in non-hatched and non-pipped chick's muscle at the red light, however, this increase was less when compared to the exposure to blue color light, which revealed a significant increase compared to non-hatched non-pipped chicks in a dark condition. The $M y o D 1$ mRNA levels were significantly upregulated in the group exposed to red light during incubation in nonhatched and non-pipped chicks and also increased in hatched chicks. Otherwise, the Myogenin expression level in hatched chicks exposed to red light during incubation was more than the case of using blue light. As several studies reported, $M y o D 1$ is responsible for the activation and proliferation of skeletal satellite cells, however, myogenin plays a pivotal role in myoblast differentiation (Yablonka-Reuveni and Paterson, 2001; Cao et al., 2006). Furthermore, Zhang et al. (2014) suggested that the use of green light during incubation until hatching enhanced proliferation and differentiation of skeletal muscle satellite cells in the late embryonic stage and newly hatched chicks. This enhancement was a result of an increase in $M y o D 1$ expression level on day 17 of the embryo until day 3 of hatched chicks as well as an increase in Myogenin expression level on the first day to the fifth day after 
hatch. Additionally, Halevy et al. (2006) showed that in ovo green light illumination has a stimulatory effect on skeletal muscle development in chicks during late embryogenesis and post-hatch period through enhanced proliferation and differentiation of adult myoblasts. regarding broiler chicken, a recent study reported that monochromatic green light stimulation during incubation increased the mRNA expressions of Pax7 18.77\%, MyoD, $10.85 \%$, Myf5, 13.48\%, and Myogenin, $17.79 \%$, which performed the satellite cell myogenic program (Bai et al., 2019).

Fibroblast growth factor 2 is a vital regulator of muscle cell proliferation and differentiation (Pawlikowski et al., 2017). the findings of the current study indicated that red light significantly increased $F G F 2$ mRNA expression level during incubation in non-hatched nonpipped chicks while in hatched chicks, blue light showed a significant increase in FGF2 mRNA expression level. Based on the results of this study, it could be suggested that the red or blue light spectrum during incubation of turkey eggs is better than darkness. Furthermore, myoblast growth may be affected by light color through its influence on myogenic regulatory genes and consequently on hatching performance.

\section{CONCLUSION}

The findings suggest that using different LED light colors (red and blue) during the incubation period may affect myogenesis through its effect on the expression profiles of muscle growth marker genes. However, there should be future studies addressing the effect of light color on the intracellular events, such as the expression of Myogenin $M y o D 1$ and $F G F 2$.

\section{DECLARATIONS}

\section{Authors' contributions}

Walaa Slouma Hamouda Abd El Naby and Heba Abdo Basha designed the plan of methodology, performed the experimental work, and wrote the main draft of the manuscript. Samya Erian Ibrahim, Magda Ismail AboSamaha, collected the samples and analyzed the data. All authors critically interpreted the data, revised the manuscript, and approved the final version of the manuscript.

\section{Competing interests}

The authors declare that they have no competing interests.

\section{REFERENCES}

Abd El Naby WSH, and Basha HA (2018). Influence of lighting systems on some muscle development related genes and production traits in Japanese quail. Asian Journal of Animal and Veterinary Advances, 13: 295-300. DOI: https://scialert.net/abstract/?doi=ajava.2018.295.300

Archer GS (2015). Timing of light exposure during incubation to improve hatchability, chick quality and post-hatch well-being in broiler chickens: 21 or 18 days. International Journal of Poultry Science, 14: 293-299. DOI: https://scialert.net/abstract/?doi=ijps.2015.293.299

Archer GS (2017). Exposing broiler eggs to green, red and white light during incubation. Animal, 11: 1203-1209. Available at: https://www.pubmed.ncbi.nlm.nih.gov/28173889/

Archer GS, and Mench JA (2014). The effects of the duration and onset of light stimulation during incubation on the behavior, plasma melatonin levels, and productivity of broiler chickens. Journal of Animal Science, 92: 1753-1758. DOI: https://www.doi.org/10.2527/jas.2013-7129

Bai X, Cao J, Dong Y, Wang Z, and Chen Y (2019). Melatonin mediates monochromatic green light-induced satellite cell proliferation and muscle growth in chick embryo. PLOS ONE, 14: e0216392. DOI: https://www.doi.org/10.1371/journal.pone.0216392

Biressi S, and Rando TA (2010). Heterogeneity in the muscle satellite cell population. Seminars in Cell and Developmental Biology, 21: 845-854. DOI: https://www.doi.org/10.1016/j.semcdb.2010.09.003

Bruzual JJ, Peak SD, Brake J, and Peebles ED (2000). Effects of relative humidity during incubation on hatchability and body weight of broiler chicks from young breeder flocks. Poultry Science, 79: 827830 . Available

https://www.pubmed.ncbi.nlm.nih.gov/10875763/

Buckingham M, and Rigby PWJ (2014). Gene regulatory networks and transcriptional mechanisms that control myogenesis. Developmental Cell, 28: 225-238. Available at: https://www.pubmed.ncbi.nlm.nih.gov/24525185

CaoY, Kumar RM, Penn BH, Berkes, CA, Kooperberg C, Boyer LA, Richard AY, and Stephen JT (2006). Global and gene-specific analyses show distinct roles for myod and myog at a common set of promoters. EMBO Journal, 8(25): 502-511. Available at: https://www.ncbi.nlm.nih.gov/pmc/articles/PMC1383539/

Cooper CB, Voss MA, Ardia DR, Austin SH, and Douglas Robinson W (2011). Light increases the rate of embryonic development: implications for latitudinal trends in incubation period. Functional Ecology, 25: 769-776. Available at: https://www.jstor.org/stable/41239356

Cornelison DD, and Wold BJ (1997). Single-cell analysis of regulatory gene expression in quiescent and activated mouse skeletal muscle satellite cells. Developmental Biology, 191: 270-283. Available at: https://www.pubmed.ncbi.nlm.nih.gov/9398440/

Elibol O, and Brake J (2006). Effect of egg turning angle and frequency during incubation on hatchability and incidence of unhatched broiler embryos with head in the small end of the egg Poultry Science, 85: DOI: https://www.doi.org/10.1093/ps/85.8.1433

El-Komy HE, Taha AE, Basha HA, Abo-Samaha MI, and Sharaf MM (2017). Pre-hatch Performance of Japanese Quails and Cobb500 Broiler Breeder Eggs Incubated Surrounded by Different Light Color Environments. Alexandria Journal of Veterinary Science, 55(2): 107-112. Available at https://www.bibliomed.org/?mno=281304

Fairchild B, and Christensen V (2000). Photostimulation of turkey eggs accelerates hatching times without affecting hatchability, liver or 
heart growth, or glycogen content. Poultry Science 79:1627-1631. DOI: https://www.doi.org/10.1093/ps/79.11.1627

Halevy O, Piestun Y, Rozenboim I, and Yablonka-Reuveni Z (2006). In ovo exposure to monochromatic green light promotes skeletal muscle cell proliferation and affects myofiber growth in posthatch chicks. The American Journal of PhysiologyRegulatory, Integrative and Comparative Physiology, 290(4): 10621070. DOI: https://www.doi.org/10.1152/ajpregu.00378.2005

Huth JC, Archer GS (2015). Effects of led lighting during incubation on layer and broiler hatchability, chick quality, stress susceptibility and post-hatch growth. Poultry Science, 94(12): 3052-3058. DOI: https://www.doi.org/10.3382/ps/pev29

Noiva RM, António C, Menezes AC, and Peleteiro MC (2014). Influence of temperature and humidity manipulation on chicken embryonic development. BMC Veterinary Research, 10: 234. Available at: http://www.biomedcentral.com/1746-6148/10/234

Okur N, Eratalar SA, and Eleroğlu H (2018). Effects of egg shell temperature and incubator ventilation programme on incubation results of broiler breeders. Turkish Journal of Agriculture-Food Science and Technology, 6(5): 536-542. DOI: https://www.doi.org/10.24925/turjaf.v6i5.536-542.1679

Pawlikowski B, Vogler TO, Gadek K, and Olwin BB (2017). Regulation of skeletal muscle stem cells by fibroblast growth factors. Developmental Dynamics, 246(5): 359-367. Available at: https://www.pubmed.ncbi.nlm.nih.gov/28249356/

Rao X, Huang X, Zhou Z, and Lin X (2013). An improvement of the 2 ^ (-delta delta CT) method for quantitative real-time polymerase chain reaction data analysis. Biostatistics, Bioinformatics and Biomathematics, 3: 7185. Available at: https://www.ncbi.nlm.nih.gov/pmc/articles/PMC4280562/

Relaix F (2006). Skeletal muscle progenitor cells: from embryo to adult. cell molecular life science, 63(11):1221-1255. DOI: https://www.doi.org/10.1007/s00018-006-6015-9

Rozenboim I, El Halawani M.E, Kashash Y, Piestun Y, and Halevy O (2013). The effect of monochromatic photo stimulation on growth and development of broiler birds. General and Comparative Endocrinology, 190: 214-219. DOI: https://www.doi.org/10.1016/j.ygcen.2013.06.027

Santos CEF (2019). Impact of light during laying hen egg incubation, on hatch traits, growth and behaviour. Master thesis, Thesis of Science in the Department of Animal and Poultry Science, University of Saskatchewan Saskatoon, SK, Canada. Available at: https://harvest.usask.ca/bitstream/handle/10388/12148/FERREIRA DOSSANTOS-THESIS-2019.pdf?isAllowed $=\mathrm{y} \&$ sequence $=1$

Schultz E, and McCormick KM (1994). Skeletal muscle satellite cells. Reviews of Physiology, Biochemistry and Pharmacology,
123: 213-257. Available at: https://pubmed.ncbi.nlm.nih.gov/8209136/

Shafey T (2004). Effect of lighted incubation on embryonic growth and hatchability performance of two strains of layer breeder eggs. British Poultry Science, 45, (2). DOI: https://www.doi.org/10.1080/00071660410001715821

Shafey T, and Al-Mohsen T (2002). Embryonic growth, hatching time and hatchability performance of meat breeder eggs incubated under continuous green light. Asian-Australian Journal of Animal Science,

15: $1702-1707$. DOI: $\underline{\text { https://www.doi.org/10.5713/ajas.2002.17 }}$

Tong QMC, Gonnell M, Romanini CEB, Bergoug H, Roulston N, Exadaktylos V, Bahre C, Berckmanse D, and Demmers TGM (2015). Higher levels of CO2 during late incubation alter the hatch time of chicken embryos. British Poultry Science, 56(4): 503-509. DOI: https://www.doi.org/10.1080/00071668.2015.1041097

Velleman SG (1999). The role of the extracellular matrix in skeletal muscle development. Poultry Science, 78: 778-784. DOI: https://www.doi.org/10.1093/ps/78.5.778

Yablonka-Reuveni Z, and Paterson BM (2001). MyoD and myogenin expression patterns in cultures of fetal and adult chicken myoblasts. Journal of Histochemistry and Cytochemistry, 49: 455-462. DOI:https://www.doi.org/10.1177/002215540104900405

Yang YF, Jiang JS, Pan JM, Ying YB, Wang X, Zhang ML, and Chen X (2016). The relationship of spectral sensitivity with growth and reproductive response in avian breeders (Gallus gallus). Scientific $\begin{array}{llll}\text { Reports, } & 6 \text { : } & \text { 19291-19300. }\end{array}$ https://www.doi.org/10.1038/srep19291

Yun Y, Won JE, Jeon E, Lee S, Kang W, Jo H, Jo H, Jang J, Shin US, and Kim H (2010). Fibroblast Growth Factors: Biology, Function, and Application for Tissue Regeneration. Journal of tissue engineering, 7: Article ID 218142. DOI: https://www.doi.org/10.4061/2010/218142

Zammit PS (2017). Function of the myogenic regulatory factors Myf5, MyoD, Myogenin and MRF4 in skeletal muscle, satellite cells and regenerative myogenesis. Seminars in Cell and Developmental Biology, 72: 19-32. Available at: https://www.pubmed.ncbi.nlm.nih.gov/29127046/

Zhang L, Zhang HJ, Wang J, Wu SG, Qiao X, Yue HY, Yao JH, Qi GH (2014). Stimulation with monochromatic green light during incubation alters satellite cell mitotic activity and gene expression in relation to embryonic and posthatch muscle growth of broiler chickens. Animal, 8(1):8693. DOI: https://www.doi.org/10.1017/S1751731113001882

Zhang L, Zhu XD, Wang XF, Li JL, Gao F, Zhou GH (2016). Green Lightemitting Diodes Light Stimuli during Incubation Enhances Posthatch Growth without Disrupting Normal Eye Development of Broiler Embryos and Hatchlings. Asian-Australasian Journal of Animal Sciences, 29(11):1562-1568. DOI: https://www.doi.org/10.5713/ajas.15.0976 